\title{
Influence of Process Parameters on Zinc Powder Produced by Centrifugal Atomisation
}

\author{
Phairote Sungkhaphaitoon $^{a}$, Sirikul Wisutmethangoon ${ }^{b}$, Thawatchai Plookphol $^{c *}$ \\ ${ }^{a}$ Department of Materials Science and Technology, Faculty of Science, \\ Prince of Songkla University, Hat Yai 90112, Thailand \\ ${ }^{b}$ Department of Mechanical Engineering, Faculty of Engineering, \\ Prince of Songkla University, Hat Yai 90112, Thailand \\ ${ }^{c}$ Department of Mining and Materials Engineering, Faculty of Engineering, \\ Prince of Songkla University, Hat Yai 90112, Thailand
}

Received: November 07, 2015; Revised: January 18, 2017; Accepted: March 11, 2017

\begin{abstract}
An experimental centrifugal atomiser was used to study the manufacture of zinc powder. Melt temperature, melt flow rate, rotating speed and diameter of the atomising disc, are operating parameters that were varied, and their effects on powder quality and yield were observed. The median particle size and the particle size distribution tended to be better, i.e. smaller and narrower, with increasing rotating speed, melting temperature, and atomising disc size. With decreasing melt flow rate, the median particle size decrease and the particle size distribution is similar, all curves are almost overlapping. The yield of zinc powder increased with rotating speed and disc size, and decreased with melt flow rate. Apparent densities of zinc powder were in the range from 1.65 to $2.51 \mathrm{~g} / \mathrm{cm}^{3}$. In SEM micrographs most zinc particles were irregular in shape, and the particle structure was mainly cellular based on optical imaging after etching of a polished surface.
\end{abstract}

Keywords: Centrifugal atomisation; Zinc powder; Particle size distribution; Apparent density

\section{Introduction}

Zinc powder is used in many applications including lubricants, chemical formulations, protective coatings, paints, brake linings and alkaline batteries ${ }^{1,2}$. Proper size and shape of particles for each application can be approached by selecting the manufacturing method, and further processing of the powder. The evaporation-condensation method produces metal powders with fine particles of regular spherical shape, but leaves impurities in the metal powders. The electrochemical method allows the production of fine particles with flake shape and high purity. Gas atomisation, water atomisation, ultrasonic atomisation and centrifugal atomisation are atomisation processes, used to produce metal powders with fine particles and high purity ${ }^{2}$. Centrifugal atomisation has an advantage over gas, water, and ultrasonic atomisation, in that it can fabricate metal powder with spherical particle shape and narrow size distribution, with low impurity and high productivity $^{3}$. It also has the lowest cost of these atomisation processes, because of its low energy consumption and not needing the parts that manipulate the atomising fluid medium 4,5. Centrifugal atomisation has been successfully used for processing a wide range of metals including $\mathrm{Sn}, \mathrm{Pb}, \mathrm{Al}$, $\mathrm{Mg}, \mathrm{Ti}, \mathrm{Ni}, \mathrm{Co}, \mathrm{Zn}$ and their alloys ${ }^{3,6,7}$. Therefore this study focuses on centrifugal atomisation to produce zinc powder. In centrifugal atomisation molten metal is directly injected onto a spinning disc, and it forms a film on the surface of this atomising disc. The thickness of the fluid film depends

\footnotetext{
* e-mail: thawatchai.p@psu.ac.th
}

on the fluid flow rate, disc rotation speed, disc radius, disc slope angle and its properties such as density, viscosity and surface tension. The thickness of the fluid film at the disc edge decreases with decreasing melt flow rate, disc slope angle and with increasing disc rotation speed, disc radius ${ }^{8}$. At the edge of the spinning disc, the film begins to break up to small droplets as shown in figure 1. For the disintegration process of spreading melt in centrifugal atomisation relates between the disc radius $\left(r_{o}\right)$, ligament formation radius $\left(r_{c 1}\right)$ and droplet formation radius $\left(r_{c 2}\right)$. The melt can be disintegrated before reaching the edge of the disc when the dynamic contact angle of the melt exceeds a critical contact angle (a non-fully spreading melt on the atomising disc, $r_{o}>$ $\left.r_{c l}\right)$. For a fully spreading melt $\left(r_{o}<r_{c l}\right)$, the disintegration of melt is expected to take place near the edge of the disc. For a flat disc, the critical contact angle increases with increasing melt flow rate and decreasing disc rotation speed ${ }^{9}$. There are three different disintegration modes: direct drop formation (DDF), ligament disintegration (LD) and film disintegration (FD). These atomisation modes lead respectively to spheres and spheroids, ligaments, or sheets, as the particle shapes in the powder ${ }^{5,9-12}$. The diameter of droplets has been predicted using equation (1) ${ }^{4}$.

$$
d=\sqrt{\frac{6 \gamma}{\rho \omega^{2} R}}
$$

where $\gamma$ is the surface tension $(\mathrm{N} / \mathrm{m}), \rho$ is the density $(\mathrm{kg} /$ $\left.\mathrm{m}^{3}\right), \omega$ is the angular velocity $(\mathrm{rad} / \mathrm{s})$ and $R$ is the atomiser disc radius (m). This equation implies that droplet diameter 


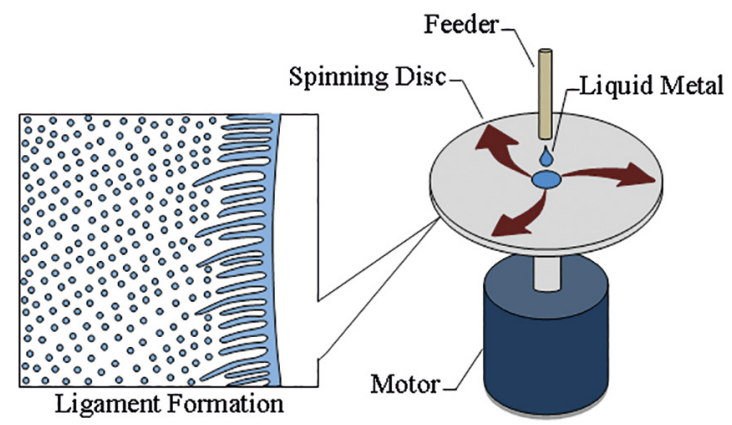

Figure 1. A schematic diagram of centrifugal atomisation ${ }^{16}$.

decreases with angular speed. However, equation (1) does not include the effects of liquid flow rate, which will through disintegration mode changes affect the droplet size ${ }^{12,13}$. In 1981, Champagne and Anger ${ }^{14}$ suggested the empirical equation (2) for predicting the median particle size from centrifugal atomisation, including the effects of liquid flow rate.

$$
d_{50}=\frac{3.65}{\omega D_{a}^{0.58}}\left(\frac{\gamma}{\rho}\right)^{0.46} Q^{0.06}
$$

where $d_{50}$ is the (mass based) median particle size (m), $D_{a}$ is the disc diameter $(\mathrm{m})$ and $Q$ is the liquid flow rate $\left(\mathrm{m}^{3} / \mathrm{s}\right)$. The equation holds for bare numbers with the specified units, unlike equation (1) where arbitrary units can be substituted in the equation. Shemyakina et al. proposed in 1992 the empirical equation (3) ${ }^{15}$.

$$
d_{50}=\frac{4.27 \times 10^{6}}{(2 \pi \eta / 60)^{0.95} d^{0.61}}\left(\frac{\theta}{\rho}\right)^{0.42}\left(\frac{Q^{0.12}}{10^{6}}\right)
$$

where $\eta$ is the disc rotation rate (rpm), $d$ is the disc diameter $(\mathrm{m})$, and $\theta$ is the surface tension $(\mathrm{N} / \mathrm{m})$. The present work aimed to study the effects of melt flow rate, angular speed and diameter of the atomising disc, on the median particle size, production yield, apparent powder density, morphology and microstructure of zinc metal particles.

\section{Experiment Procedures}

\subsection{Centrifugal atomiser}

An experimental centrifugal atomiser was fabricated and used in our laboratory to study the influence of operating parameters on some characteristics of zinc powder. As schematically shown in figure 2 , on operating this centrifugal atomisation unit the following 10 items will be present: (1) a crucible, (2) molten metal, (3) a tundish, (4) a heater, (5) a graphite nozzle, (6) an atomising disc, (7) melt droplets, (8) a high speed motor, (9) a hot air blower, and (10) an atomiser frame box that shields the user from the hot metal. A tundish was set up on top of the atomiser to ease pouring

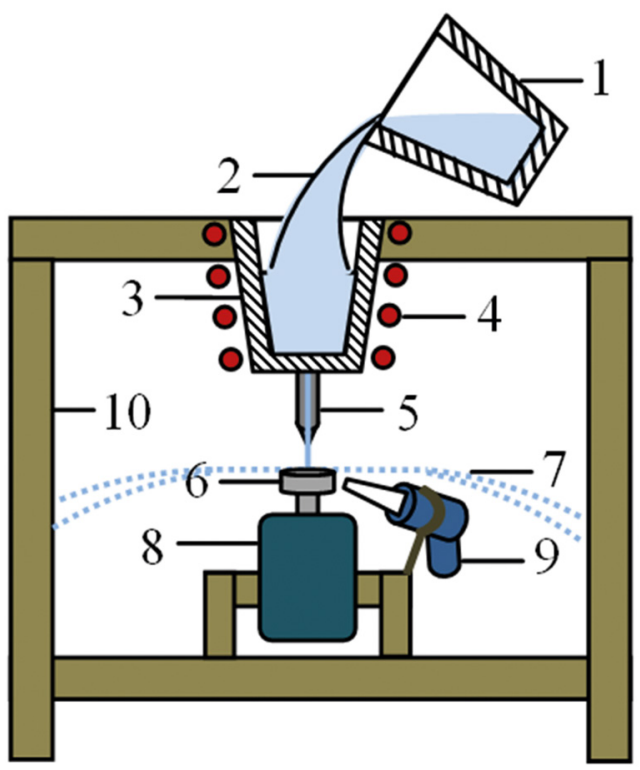

Figure 2. A schematic of the laboratory device constructed for centrifugal atomisation, in operation.

the melt in, and it was connected to a graphite nozzle, available in diameters 1.5, 2.0 and $2.5 \mathrm{~mm}$. Experimental average melt flow rates for these nozzle sizes are given in table 1. Graphite rotating discs with diameters 30, 40, 50, and $60 \mathrm{~mm}$ were used throughout the experiments. The hot air blower was used for preheating the atomiser disc before commencing atomisation. A high speed motor was controlled by a voltage regulator with rotation speed detected by an inductive proximity sensor that gave a pulse for each rotation. The speeds used in the experiment were in the range 10,000-30,000 rpm.

\subsection{Materials}

Commercial grade zinc ingots were supplied by Padaeng Industry Company, Thailand. The chemical composition of the ingots is given in table 2. Zinc metal having a melting temperature of $419.5^{\circ} \mathrm{C}$. Density and surface tension of the zinc metal at $450{ }^{\circ} \mathrm{C}$, reported by Pstrus et al., are $6,508 \mathrm{~kg} /$ $\mathrm{m}^{3}$ and $0.802 \mathrm{~N} / \mathrm{m}$, respectively ${ }^{17}$.

\subsection{Experiment}

The experiment commenced with melting $1.0 \mathrm{~kg}$ zinc ingots in a furnace at $450-550{ }^{\circ} \mathrm{C}$ temperature. When the molten zinc had reached the target temperature, the atomiser disc was preheated to $300^{\circ} \mathrm{C}$. Prior to atomisation, the high speed motor was turned on and set to a predetermined rotational speed, by adjusting the supplied voltage across the motor terminal. Then, the molten zinc metal was transferred and poured into the tundish. Gravity fed the melt through the nozzle onto the rotating atomiser disc, and small droplets were 
Table 1. Average melt flow rates for different nozzle sizes

\begin{tabular}{lccc}
\hline Nozzle size $(\mathrm{mm})$ & 1.5 & 2.0 & 2.5 \\
\hline Melt flow rate $(\mathrm{kg} / \mathrm{hr})$ & 50.47 & 81.66 & 121.38 \\
\hline
\end{tabular}

Table 2. Chemical composition of zinc ingot

Chemical composition (wt. \%)

\begin{tabular}{ccccccc}
$\mathrm{Zn}$ & $\mathrm{Pb}$ & $\mathrm{Cd}$ & $\mathrm{Fe}$ & $\mathrm{Cu}$ & $\mathrm{Al}$ & $\mathrm{Sn}$ \\
\hline 99.995 & 0.003 & 0.003 & 0.002 & 0.001 & 0.001 & 0.001 \\
\hline
\end{tabular}

formed, and rapidly solidified due to heat convection to the surrounding environs and all the experiments were carried out in air. The run duration was recorded for estimating the average melt flow rate. After the experiment, about $200 \mathrm{~g}$ of zinc powder was sampled by coning and quartering method to be analysed for the particle size distribution, median particle size, and production yield, by sieve shaker model Octagon digital (ASTM E11) in a $10 \mathrm{~min}$ run. The production yield was defined as the mass fraction of powder with particle sizes from 25 to $212 \mu \mathrm{m}$. The shapes of particles in the yield were examined using scanning electron microscope (SEM) model Quanta 400. The apparent density of the yield was determined with Carney funnel (ASTM B417). The microstructure of zinc particles was observed by optical microscopy (OM). The particles were cold mounted using epoxy resin and a polished surface created by grinding and polishing with a grinder-polisher model Metkon Digiset-2V, then etched by immersion in $5 \mathrm{ml} \mathrm{HNO}_{3}$ mixed with 100 $\mathrm{ml} \mathrm{H}_{2} \mathrm{O}$ for 2 seconds ${ }^{18}$, before rinsing with distilled water to prevent further etching.

\section{Results and Discussion}

The effects of atomising speed, atomising disc and melt flow rate on median particle size, particle size distribution, particle morphology and apparent density of zinc powder produced by centrifugal atomisation are discussed in the following paragraphs.

\subsection{Effects of rotating speed}

The effects of atomising disc speed on median particle size and size distribution of zinc powder are illustrated in figures 3-4. The particles became finer with increasing angular speed because of increased centrifugal force that spreads the liquid metal film on the surface of the disc ${ }^{5}$. This is consistent with prior results on the atomisation of tin ${ }^{3}$, magnesium alloy ${ }^{11}$, aluminum ${ }^{19}$, and lead-free solder alloy ${ }^{20}$. The particle size from the present study is compared with that calculated by using empirical models shown in equations. (1) - (3). It is observed that the median particle size of produced zinc powder from the present study is larger than that predicted by the models. The discrepancy of median particle size of the present study from the previous models may result from slippage of melt on the surface of the atomising disc because in the experiments, a flat disc was used, which provides a very small critical contact angle. As a result the non-fully wetting melt on a flat disc is most likely to disintegrate well before reaching the disc edge and thus big droplets ${ }^{9}$. The slippage of melt depends on density of melt and wetting of the disc surface with melt ${ }^{19}$. The wetting between melt and disc surface can be improved by coating with the material being atomised; the coated disc will have less slippage leading to a decrease in the median particle size ${ }^{20}$. The size distributions in figure 4 vary in their shapes and not only the medians, with steeper slopes at higher speeds indicating narrowing of size distribution. In the general practice of powder fabrication, a single sized or monodisperse powder cannot be formed, instead a typical powder product is polydisperse with a wide range of particle sizes ${ }^{21}$.

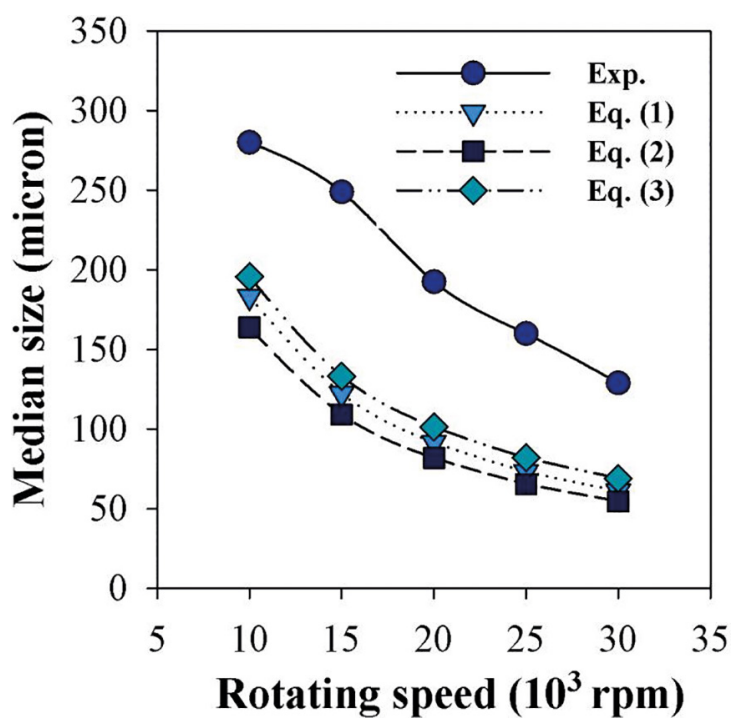

Figure 3. Effect of rotation speed on mass based median particle size, with $40 \mathrm{~mm}$ diameter flat disc, $50 \mathrm{~kg} / \mathrm{hr}$ melt feed rate, and $550{ }^{\circ} \mathrm{C}$ melt temperature.

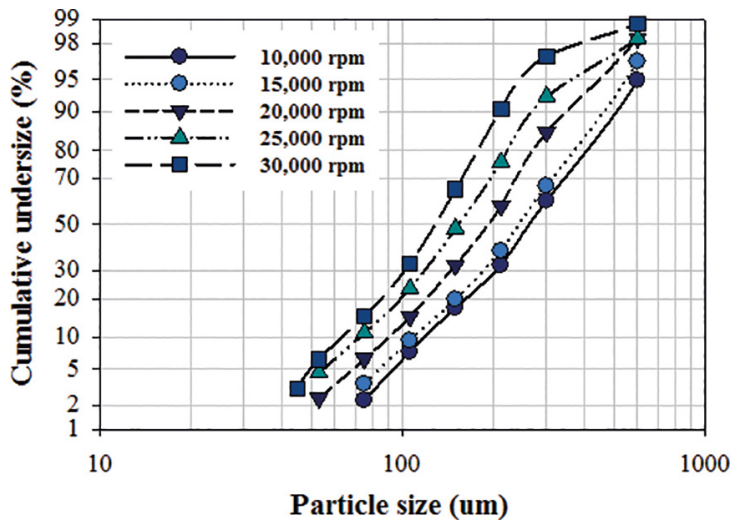

Figure 4. Effect of rotation speed on cumulative mass distribution by particle size. Disk diameter $40 \mathrm{~mm}, 50 \mathrm{~kg} / \mathrm{hr}$ melt feed rate, and $550{ }^{\circ} \mathrm{C}$ melt temperature. 


\subsection{Effects of atomising disc size}

Disc diameters 30, 40, 50, and $60 \mathrm{~mm}$ were used in the atomisation process, with fixed $30,000 \mathrm{rpm}$ rotating speed, $550{ }^{\circ} \mathrm{C}$ melt temperature and $50 \mathrm{~kg} / \mathrm{hr}$ melt flow rate. It is noted that in the first set of experiments, the $30,00 \mathrm{rpm}$ rotating speed gave a smaller median particle size and higher powder production yield. Also at lower melt flow rate a thinner melt film can be formed on the rotating disc, which is resulting to the formation of smaller melt droplets, and leading to smaller median size of the produced powder ${ }^{3,9,15}$. So, the $30,000 \mathrm{rpm}$ rotating speed and $50 \mathrm{~kg} / \mathrm{hr}$ melt flow rate were chosen for the experiments to study the effects of atomising disc size. The median particle size of atomised zinc powder decreased with disc diameter as shown in figure 5 , in agreement with previous studies ${ }^{5,20}$. A larger disc has a higher centrifugal force at the edge, so the disintegration velocity of melt is higher, making smaller particles. The variation of particle size with rotating disc speed from the present study is compared with those predicted from the empirical equations (1) - (3) in figure 5. The median size measured from the experiment in the present study is larger than that predicted from the equations ${ }^{20}$. This discrepancy may result from the slippage of melt on the surface of atomising disc as discussed in the previous section. The particle size distributions are shown in figure 6.

\subsection{Effects of melt flow rate}

Figure 7 shows the median particle sizes of zinc powder atomised with melt flow rates 50,80 and $120 \mathrm{~kg} / \mathrm{hr}$, at 550 ${ }^{\circ} \mathrm{C}$ melt temperature, 30,000 rpm rotating speed, and 60 $\mathrm{mm}$ disc size. The median size increased slightly with melt

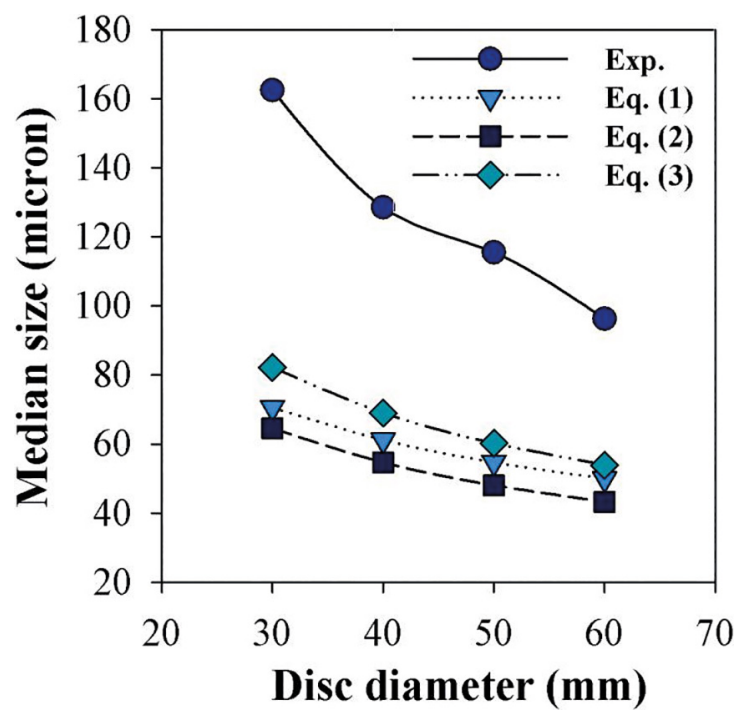

Figure 5. Effect of atomising disc diameter on median particle size. Rotating speed $30,000 \mathrm{rpm}, 50 \mathrm{~kg} / \mathrm{hr}$ melt feed rate, and 550 ${ }^{\circ} \mathrm{C}$ melt temperature.

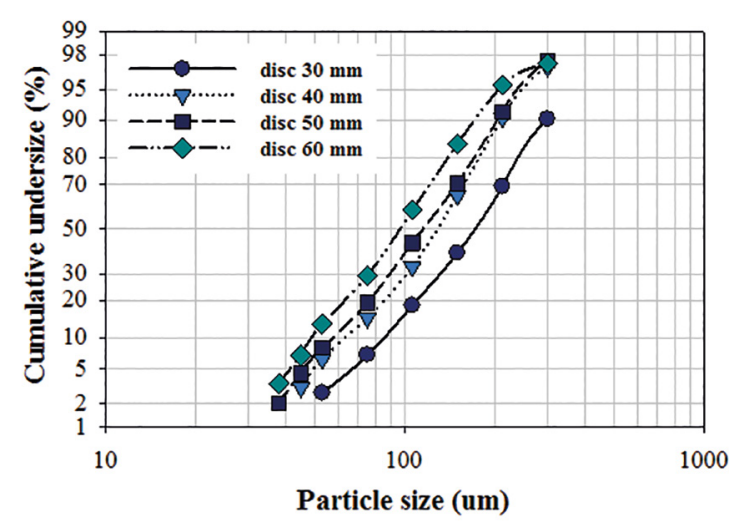

Figure 6. Effect of atomising disc diameter on particle size distribution. Rotating speed $30,000 \mathrm{rpm}, 50 \mathrm{~kg} / \mathrm{hr}$ melt feed rate, and $550{ }^{\circ} \mathrm{C}$ melt temperature.

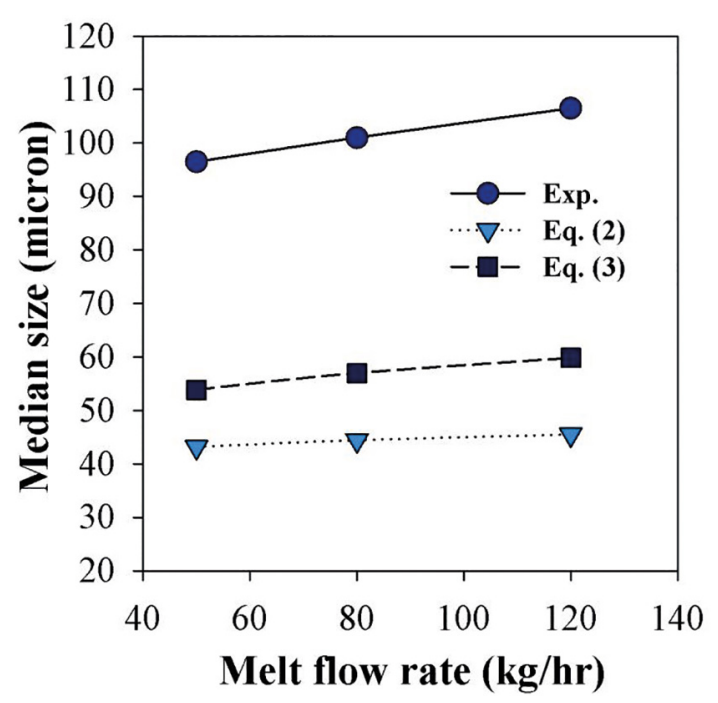

Figure 7. Effect of melt flow rate on median particle size. Rotating speed $30,000 \mathrm{rpm}, 60 \mathrm{~mm}$ disc diameter, and $550^{\circ} \mathrm{C}$ melt temperature.

flow rate ${ }^{5,20}$. This result is consistent with prior report by Xie et al. has shown that decreasing the melt flow rate lead to decreased size of the atomised droplets because the film thickness at the disc edge decreases and the breakage of melt film becomes easier; hence the droplets are finer ${ }^{3}$. However, a minimum melt flow rate beyond which varying the flow rate has no effect on the droplet size distribution ${ }^{9}$. The measured particle size from the present study is compared with that calculated by the empirical models, equation (2) and equation (3) as shown in figure 7 . The particle size from the present study is larger than that predicted from the equations. This result is similar to the effect of rotating speed and atomising disc size on the particle size as discussed previously in the section 3.1. Figure 8 shows the size distributions at different melt flow rate. The size distributions are similar, all curves are almost overlapping. This result is consistent with prior report by Halada and Suga ${ }^{13}$. 


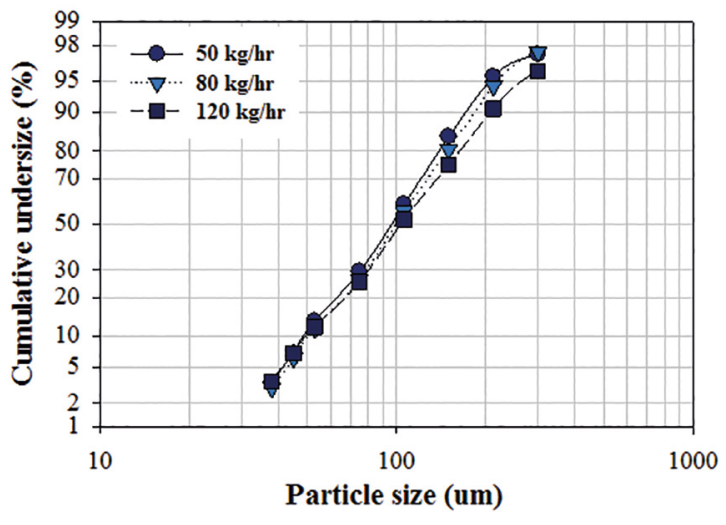

Figure 8. Effect of melt flow rate on particle size distribution. Rotating speed $30,000 \mathrm{rpm}, 60 \mathrm{~mm}$ diameter disc, and $550{ }^{\circ} \mathrm{C}$ melt temperature.

\subsection{Production yield}

Figures 9-11 shows the effects of operating parameters on yield percentages of zinc powder. The production yield in this study was defined as the mass fraction of zinc powder with particle sizes from 25 to $212 \mu \mathrm{m}$. The yield increased with disc speed and diameter, and decreased with melt flow rate. This result is consistent with prior reports on the atomisation of AA2014 alloy, $\mathrm{Sn}, \mathrm{Pb}, \mathrm{Zn}$, and Al powders ${ }^{5}$, and lead free solder alloy ${ }^{20}$. The highest yield achieved was about $94 \%$.

\subsection{Apparent density of zinc powder}

Apparent density of a metal powder is an important characteristic of this raw material, because it affects the strength of the work piece after powder forming. Usually, the apparent density decreases with decreasing particle

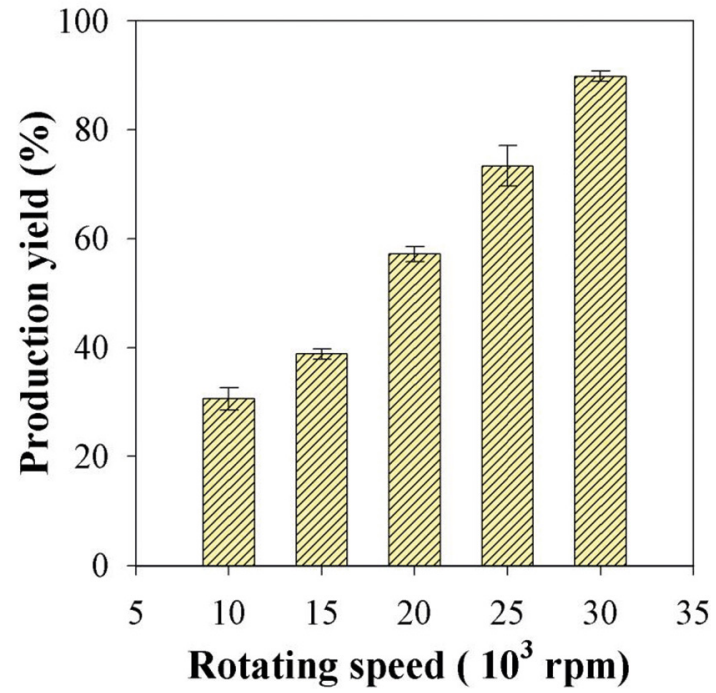

Figure 9. Effect of rotation speed on production yield of zinc powder, with $40 \mathrm{~mm}$ diameter flat disc, $50 \mathrm{~kg} / \mathrm{hr}$ melt feed rate, and $550{ }^{\circ} \mathrm{C}$ melt temperature.

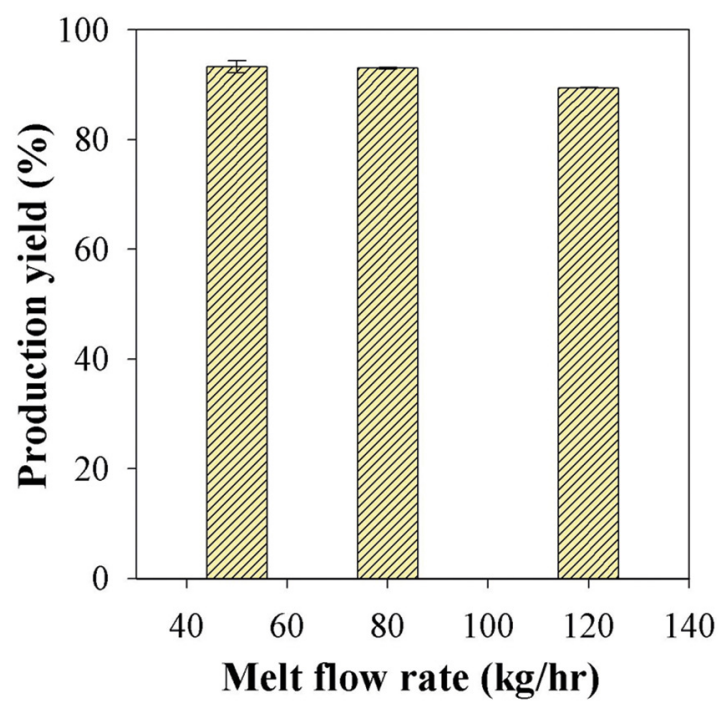

Figure 10. Effect of melt flow rate on production yield of zinc powder, with 30,000 rpm rotating speed, $60 \mathrm{~mm}$ diameter disc, and $550{ }^{\circ} \mathrm{C}$ melt temperature.

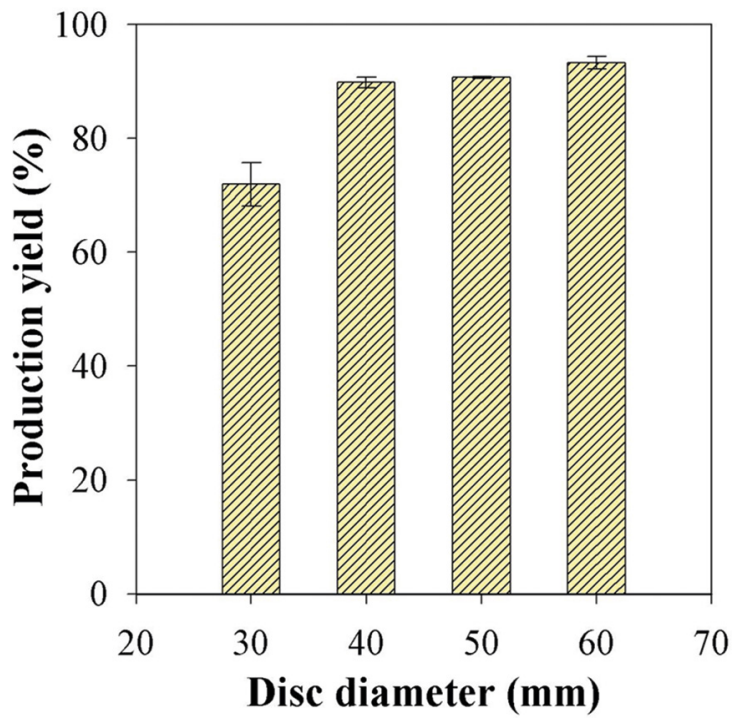

Figure 11. Effect of atomising disc diameter on production yield of zinc powder with $30,000 \mathrm{rpm}$ rotating speed, $50 \mathrm{~kg} / \mathrm{hr}$ melt feed rate, and $550{ }^{\circ} \mathrm{C}$ melt temperature.

size, increasing surface roughness, more irregular shaped particles, and depends on the particle size distribution ${ }^{22}$. In the present study the apparent densities of zinc powder, produced by centrifugal atomisation, were in the range of $1.65-2.51 \mathrm{~g} / \mathrm{cm}^{3}$, as shown in table 3 . In a previous study on zinc powder production by air atomisation, an apparent density of $3.0 \mathrm{~g} / \mathrm{cm}^{3}$ was achieved ${ }^{2}$. For commercial grade zinc powder used in powder metallurgy parts, diamond tools, friction materials, and catalysts produced by air atomisation process, the particle sizes must be in the range of $25-200 \mu \mathrm{m}$ with an apparent density of $2.10-3.05 \mathrm{~g} / \mathrm{cm}^{3}$, respectively ${ }^{23}$. 
Table 3. Apparent densities of zinc powders, determined by Carney funnel

\begin{tabular}{lc}
\hline Parameters & Apparent density $\left(\mathrm{g} / \mathrm{cm}^{3}\right)$ \\
\hline Melt temperature $550^{\circ} \mathrm{C}$ & \\
Flow rate $50 \mathrm{~kg} / \mathrm{hr}$ & \\
Atomising disc $40 \mathrm{~mm}$ & \\
Speed (rpm) & \\
10,000 & 2.51 \\
15,000 & 2.03 \\
20,000 & 2.10 \\
25,000 & 1.98 \\
30,000 & 1.66 \\
\hline
\end{tabular}

Melt temperature $550^{\circ} \mathrm{C}$

Speed 30,000 rpm

Atomising disc $60 \mathrm{~mm}$

Flow rate $(\mathrm{kg} / \mathrm{hr})$

50

80

2.13

120

2.16

Melt temperature $550^{\circ} \mathrm{C}$

Flow rate $50 \mathrm{~kg} / \mathrm{hr}$

Speed 30,000 rpm

Atomising disc (mm)

30

1.71

40

1.65

50

1.98

60

2.00

\subsection{Morphology and microstructure of zinc particles}

Figure 12 shows SEM images of the zinc particles in two different size categories, (a-b) smaller sizes $(25-53 \mu \mathrm{m})$, and (c-d) larger sizes (53-212 $\mu \mathrm{m})$. Most zinc particles were irregular, elongated flakes in shape, with a minor fraction of teardrop shape. Spherical shaped particles were not observed in this study, owing to oxidation on the surface of a droplet during atomisation in air $^{5}$. The oxide film is known to prevent spheroidisation of the melt droplets during solidification ${ }^{19,20}$. Moreover, Angers et al. reported that during centrifugal atomisation of AZ91 alloy, the irregular particles did not form by an atomisation mechanism but by fragmentation of a solidified layer on the surface of the rotating disc. This phenomenon could be eliminated by preheating the disc and limiting convection cooling of the disc by the surrounding gas ${ }^{11}$. Figure 13 shows the microstructure of zinc particles produced by centrifugal atomisation. The microstructure was mainly cellular, the type of structure depended on the conditions of cooling of each individual particle ${ }^{24}$.

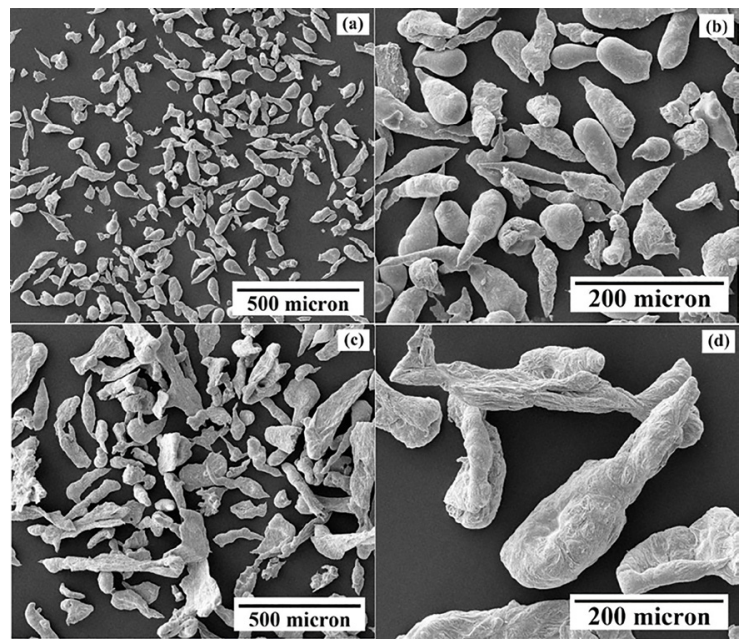

Figure 12. SEM micrographs of zinc powder. (a-b) smaller sizes $(25-53 \mu \mathrm{m})$ and $(\mathrm{c}-\mathrm{d})$ larger sizes $(53-212 \mu \mathrm{m})$.

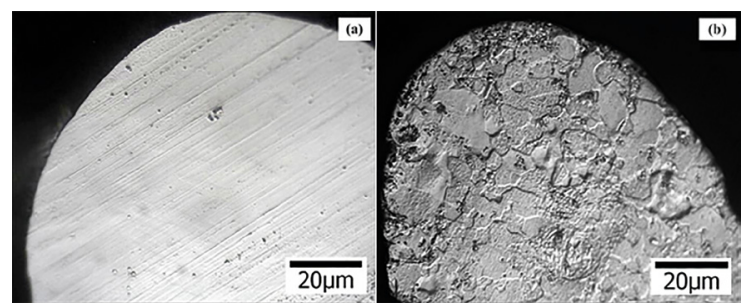

Figure 13. Optical 500x micrographs of polished zinc particles. (a) No etching, and (b) with $2 \mathrm{~s}$ etching. Etching reveals the cellular microstructure of the particle.

\section{Conclusions}

An experimental centrifugal atomiser was constructed, and applied to produce zinc powder with varying operating parameters. The experimental results indicated that:

1. The mass based median particle size decreased with rotating speed, melting temperature, and atomising disc size, and increased with melt flow rate.

2. The zinc particles produced in ambient atmosphere had cellular microstructure, and their shapes included ligaments, teardrops, flakes and irregular shapes.

3. The production yield of zinc powder, in the particle size range from 25 to 212 microns, could be increased to about $94 \%$ by using $30,000 \mathrm{rpm}$ rotating speed, $60 \mathrm{~mm}$ disc size, and $50 \mathrm{~kg} / \mathrm{hr}$ melt flow rate.

4. The apparent density of produced zinc powder was in the range from 1.65 to $2.51 \mathrm{~g} / \mathrm{cm}^{3}$.

\section{Acknowledgements}

The authors would like to thank the Department of Mining and Materials Engineering, Faculty of Engineering, Prince of Songkla University for the laboratory facilities and the 
PSU Ph.D. scholarship program for financial support. In addition, we would like to thank Associate Professor Seppo Karrila for commenting on the manuscript.

\section{References}

1. Sharifi B, Mojtahedi M, Goodarzi M, Khaki JV. Effect of alkaline electrolysis conditions on current efficiency and morphology of zinc powder. Hydrometallurgy. 2009;99(1-2):72-76.

2. Frishberg IV. Production of Zinc Cadmium and Their Alloy Powders. In: Neikov OD, Naboychenko SS, Murashova IV, Gopienko VG, Frishberg IV, Lotsko DV, eds. Handbook of Non-Ferrous Metal Powders: Technologies and Applications. Oxford: Elsevier; 2009. p. 409-420.

3. Xie JW, Zhou YY, Dunkley JJ. Effect of processing condition on powder particle size and morphology in centrifugal atomisation of tin. Powder Metallurgy. 2004;47(2):168-172.

4. Dunkley JJ, Aderhold D. Centrifugal atomization of metal powders. Advances in Powder Metallurgy and Particulate Materials. 2007;2:26-31.

5. Yule AJ, Dunkley JJ. Atomization of Melts for Powder Production and Spray Deposition. Oxford: Clarendon Press; 1994.

6. Öztürk S, Arslan F, Öztürk B. Effect of process parameters on production of metal powders by water jet cooled rotating disc atomization. Powder Metallurgy. 2005;48(2):163-170.

7. Li H, Deng X. Prediction of powder particle size during centrifugal atomisation using a rotating disc. Science and Technology of Advanced Materials. 2007;8(4):264-270.

8. Zhao YY. Analysis of flow development in centrifugal atomization: Part I. Film thickness of a fully spreading melt. Modelling and Simulation in Materials Science and Engineering. 2004;12(5):959-971.

9. Zhao YY. Analysis of flow development in centrifugal atomization: Part II. Disintegration of a non-fully spreading melt. Modelling and Simulation in Materials Science and Engineering. 2004;12(5):973-983.

10. Yue Y, Sutherland JW, Olson WW. Cutting fluid mist formation in machining via atomization mechanisms. In: Design for Manufacturing and Assembly. 1996 Asme International Mechanical Engineering Congress and Exposition; 1996 Nov 17-22; Atlanta, GA, USA. Volume 89. p. 37-46.

11. Angers R, Tremblay R, Dubé D. Formation of irregular particles during centrifugal atomization of AZ91 alloy. Materials Letters. 1997;33(1-2):13-18.
12. Neilev OD. Atomization and Granulation. In: Neikov OD, Naboychenko SS, Murashova IV, Gopienko VG, Frishberg IV, Lotsko DV, eds. Handbook of Non-Ferrous Metal Powders: Technologies and Applications. Oxford: Elsevier; 2009. p. 102-142.

13. Halada K, Suga H. Study on Parameters for Centrifugal Atomization with Atomizing Molten Zinc. Journal of the Japan Society of Powder and Powder Metallurgy. 1990;37(3):398-404.

14. Champagne B, Angers R. Size distributions of powders atomized by the rotating electrode process. In: Proceedings of the 1980 International Powder Metallurgy Conference; 1980 Jun 22-27; Washington, DC, USA. Princeton: Metal Powder Industries Federation; 1981. p. 83-104.

15. Shemyakina OA, Sheikhalieva ZI, Sheikhaliev SM. Obtaining solder powders by centrifugal atomization of melt. Russian Journal of Non-Ferrous Metals. 2010;51(3):250-254.

16. Graco, Inc. Atomization concept and theory. Available from: $<\mathrm{http}$ ://wwwd.graco.com/training/concept_and_theory/ Atomization\%20v2.pdf > . Access in: 18/3/2014.

17. Pstruś J, Moser Z, Gąsior W. Surface properties of liquid In-Zn alloys. Applied Surface Science. 2011;257(9):3867-3871.

18. Metallography and microstructure of zinc and its alloys. In: ASM International. ASM Handbook, Volume 9. Metallography and Microstructures. Materials Park: ASM International; 2004. p. $933-941$

19. Shikhaliev SM, Shikhalieva ZI, Dunkley JJ. Spin atomisation makes tighter, safer aluminium. Metal Powder Report. 2008;63(2):28-30.

20. Plookphol T, Wisutmethangoon S, Gonsrang S. Influence of process parameters on SAC305 lead-free solder powder produced by centrifugal atomization. Powder Technology. 2011;214(3):506-512.

21. German RM. Powder Metallurgy Science. $2^{\text {nd }}$ ed. Princeton: Metal Powder Industries Federation; 1994.

22. Neikov OD, Lotsko DV Gopienko VG. Powder characterization and testing. In: Neikov OD, Naboychenko SS, Murashova IV, Gopienko VG, Frishberg IV, Lotsko DV, eds. Handbook of Non-Ferrous Metal Powders: Technologies and Applications. Oxford: Elsevier; 2009.

23. Pometon Powder. Zinc Powder. Italy. Available from: $<\mathrm{http} / /$ www.pometon.com/materialsDetails_eng.php/family $=\mathrm{Non} \% 20$ Ferrous/id_cat=2/id_sottocat $=15>$. Access in: 13/3/2014 .

24. Tsipunov AG, Ternovoi YF, Kuratchenko SB, Kuimova OM. Experimental investigation of the process of powder manufacture by centrifugal atomization. Soviet Powder Metallurgy and Metal Ceramics. 1983;22(10):788-793. 